\title{
Morphological and pharmacological studies of the parietal cells of the stomach in the dog during periods of maximal acid output and after the gastric secretory inhibitor UK-9040
}

\author{
D. B. HAMER, ${ }^{1}$ A. B. PRICE, ${ }^{2}$ AND J. H. BARON ${ }^{3}$ \\ From the Department of Surgery, Royal Postgraduate Medical School, and the Department of Pathology, \\ St. Marks Hospital, London
}

SUMMARY UK-9040, a derivative of the antihistamine triprolidine, is a potent gastric secretory inhibitor. Given orally to dogs it reduced gastric acid, pepsin, and volume output in response to food, insulin, histamine, $\mathrm{N}$-methyl histamine, and pentagastrin. Doses of $6-36 \mathrm{mg} / \mathrm{kg}$ administered orally four to five hours before the secretagogues produced a dose-dependant and up to $100 \%$ inhibition in the outputs of innervated gastric fistula and denervated Heidenhain pouch. Inhibition was still present 24 hours after administration of UK-9040 but was absent at 48 hours. Blood pressure and pulse rate were not affected. Studies with the electron microscope revealed that the normal ultrastructural responses to gastric secretory stimulation were arrested. UK-9040 showed no cumulative effect, tolerance did not occur, and after withdrawal of the drug the physiological and morphological gastric responses of the parietal cells rapidly returned to normal.

The action of histamine on the gastric parietal cell is not blocked by the classical antihistamines. However, Black et al. (1972) by chemical modification of histamine itself discovered an inhibitor of gastric acid secretion, burimamide, from which have been developed metiamide and cimetidine.

An alternative approach to the identification of such inhibitors has been the modification of conventional $\mathrm{H}_{1}$ antihistamines. UK-9040 (Fig. 1) has been developed from triprolidine by Pfizer Central Research, Sandwich. We report here the effects of this compound on gastric secretion and parietal cell structure in the dog.

\section{Methods}

Four dogs with both gastric fistulas and Heidenhain pouches were trained to undergo gastric secretory

${ }^{1}$ Present address: Department of Surgery, St. Mary's Hospital, London W.2.

${ }^{2}$ Present address: Department of Histopathology, Clinical Research Centre, Northwick Park Hospital, Harrow.

${ }^{3}$ Address for correspondence: Dr J. H. Baron, Department of Surgery, Royal Postgraduate Medical School, Hammersmith Hospital, London W12 0HS.

Received for publication 9 August 1976

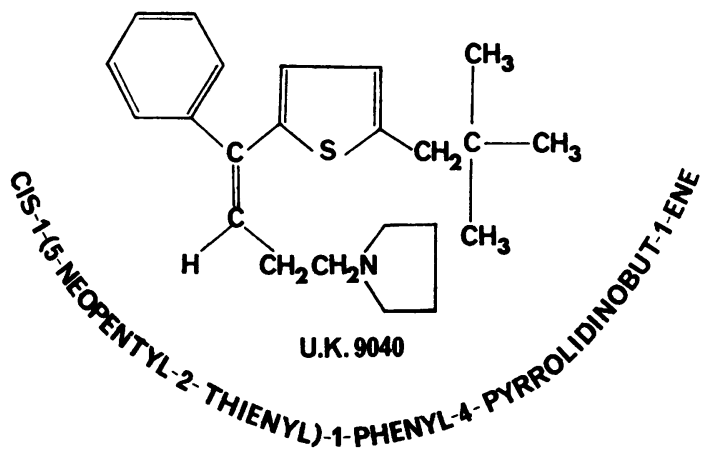

Fig. 1 Formula of UK-9040.

studies in Pavlov stands. Gastric secretion was collected in 15 minute fractions. Capsules of UK9040 were given orally after the dogs had fasted overnight.

\section{GASTRIC SECRETAGOGUES}

Food

Collections were made from the Heidenhain pouch of each dog for 30 minutes before, and three hours 
after, administration of a meal of $20 \mathrm{~g} / \mathrm{kg}$ of standard dog food. A total of seven control studies and 12 studies after administration of UK-9040 were conducted in the four dogs. UK-9040 was given in doses between 7 and $30 \mathrm{mg} / \mathrm{kg}$ four hours before administration of the meal.

\section{Insulin}

Collections were made from the gastric fistula in each dog 30 minutes before and two hours after an intravenous injection of 0.25 units $/ \mathrm{kg}$ soluble insulin. A total of 11 control studies, and 13 studies after administration of UK-9040, were conducted in the four dogs. UK-9040 was given in doses of 6 to $36 \mathrm{mg} / \mathrm{kg}$ between four and five hours before injection of the insulin.

\section{Histamine}

Histamine acid phosphate was infused intravenously in a dose of $2 \mu \mathrm{g} / \mathrm{kg}$-min for $2 \frac{1}{2}$ hours. Collections were made from both the gastric fistula and the Heidenhain pouch of each dog for 30 minutes before and during the infusion. Gastric secretion from both the fistula and the pouch maintained a plateau over the period between 30 and 150 minutes after the start of the infusion. A total of 12 control studies and 36 studies after administration of UK-9040 were conducted in the four dogs. UK-9040 was given in doses between 1 and $36 \mathrm{mg} / \mathrm{kg}$ at various intervals between one and 48 hours before the infusion of histamine. These studies were designed to assess the duration of action of UK-9040.

\section{$N$-methyl histamine}

These studies were identical with those described above for histamine, except that $\mathrm{N}$-methyl histamine was infused in a dose of $1 \mu \mathrm{g} / \mathrm{kg}$-min. Only three control studies and three studies after administration of UK-9040 were conducted because of the limited supply of N-methyl histamine. UK-9040 was given in a dose of $25 \mathrm{mg} / \mathrm{kg}$ four hours before the start of the infusion.

\section{Pentagastrin}

Pentagastrin was infused intravenously in doses of 1-32 $\mu \mathrm{g} / \mathrm{kg}$-hour for $2 \frac{1}{2}$ hours. Collections were made from both the gastric fistula and the Heidenhain pouch of each dog for 30 minutes before and during the infusion. Gastric secretion from both the fistula and the pouch maintained a plateau over the period between 30 and 150 minutes after the start of the infusion. A total of 45 control studies and 55 studies after administration of UK-9040 were conducted in the four dogs. UK-9040 was given in doses of 6 to $30 \mathrm{mg} / \mathrm{kg}$ four hours before the infusion of pentagastrin.

The volume, $\mathrm{pH}$, titratable acidity, and pepsin concentration were measured for each sample collected. Acid output in the period 30-150 minutes after the start of the pentagastrin or histamine infusion has been expressed as $\mathrm{mmol} / 2 \mathrm{~h}$.

A study of the long-term effects of UK-9040 was conducted in one dog. The dosage of UK-9040 and the timing of the studies of gastric secretion are shown in the Table.

\section{Table Chronic dosing experiment}

\begin{tabular}{lll}
\hline $\begin{array}{l}\text { Dose of } U K-9040 \\
(\mathrm{mg} / \mathrm{kg})\end{array}$ & Days of treatment* & $\begin{array}{l}\text { Day of test of gastric } \\
\text { secretory function }\end{array}$ \\
\hline 4 & $1-7$ & $1,3,7$ \\
8 & $8-12$ & 10,12 \\
25 & 15 & $16,17,19,22$ \\
25 & 23 & 24,25 \\
25 & 29 & 30,31 \\
8 & $38-53$ & 53 \\
16 & $54-95$ & $72,95,185$ \\
\hline
\end{tabular}

*Day 1 is the first day of this study.

Studies of the morphological effects of UK-9040 on the parietal cell were made on gastric mucosal biopsies. These were obtained from the lesser curve of the stomach with a Wood's biopsy tube introduced through the gastric fistula of the dog. Biopsies were taken before administration of either secretagogue or UK-9040, after administration of secretagogue and before UK-9040, and after both secretagogue and UK-9040. UK-9040 was given in a dose of 30 $\mathrm{mg} / \mathrm{kg}$ three hours before biopsy.

The biopsies were orientated on filter paper and divided. One half was fixed in $10 \%$ formalin, routinely processed for light microscopy, and stained with haematoxylin and eosin. The other half was placed in $4 \%$ methanol-free formaldehyde freshly prepared from paraformaldehyde and

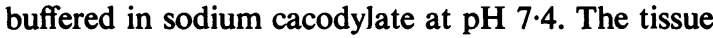
was then processed in Epon 12 and ultrathin sections were stained with lead citrate and uranyl citrate. Sections were examined in an Elmiskop A electron microscope.

In a separate experiment two dogs underwent a further operation in which a loop of the carotid artery was exteriorised and covered by a skin tube. This allowed continuous measurement of both pulse and blood pressure by direct cannulation throughout each study.

\section{Results}

The results presented are the mean values for the studies in the four dogs. 


\section{GASTRIC SECRETION STUDIES-ACID OUTPUT}

Food

Administration of UK-9040 in a dose of $8 \mathrm{mg} / \mathrm{kg}$ four hours before the meal caused a $50 \%$ inhibition of stimulated gastric acid secretion from the Heidenhain pouch (Fig. 2). At doses greater than 12.5 $\mathrm{mg} / \mathrm{kg} 100 \%$ inhibition was observed.

\section{Insulin}

A $60 \%$ inhibition of insulin stimulated acid secretion from the gastric fistula was observed with a dose of $6 \mathrm{mg} / \mathrm{kg}$ of UK-9040 (Fig. 3). At doses greater than $12.5 \mathrm{mg} / \mathrm{kg}$ inhibition approximating to $100 \%$ was observed.

\section{Histamine}

The denervated pouch was more sensitive than the innervated stomach to inhibition by UK-9040 of histamine stimulated acid secretion (Figs. 2 and 3). Thus in the innervated stomach $8 \mathrm{mg} / \mathrm{kg}$ of UK-9040 caused approximately $40 \%$ inhibition of acid output and $15 \mathrm{mg} / \mathrm{kg}$ approximately $80 \%$ inhibition. In the denervated pouch these doses produced approximately $50 \%$ and $100 \%$ inhibition respectively.

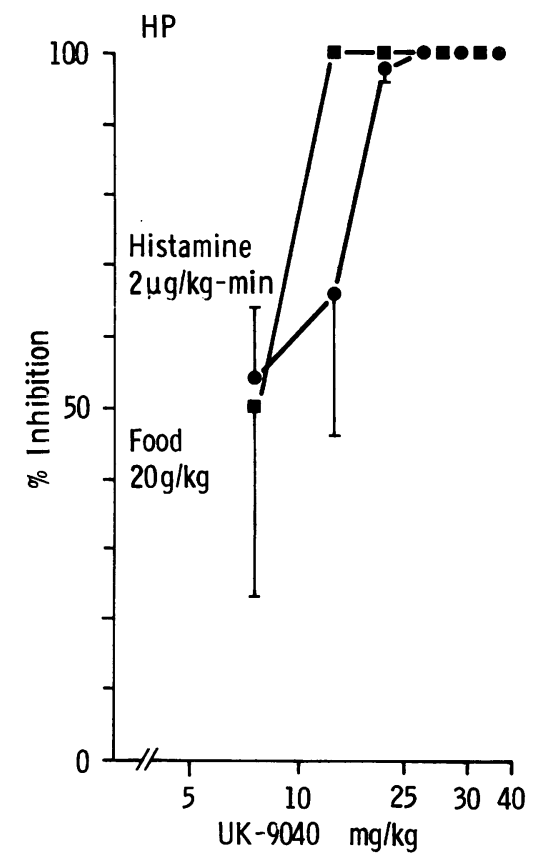

Fig. 2 Inhibition by UK-9040 given orally four hours earlier of acid secretion stimulated by histamine 2 $\mu \mathrm{g} / \mathrm{kg}$-min, insulin 0.25 units $/ \mathrm{kg}$ and food $20 \mathrm{~g} / \mathrm{kg}$ in the denervated preparation: dose response. In this and subsequent studies the mean +1 SEM are shown.

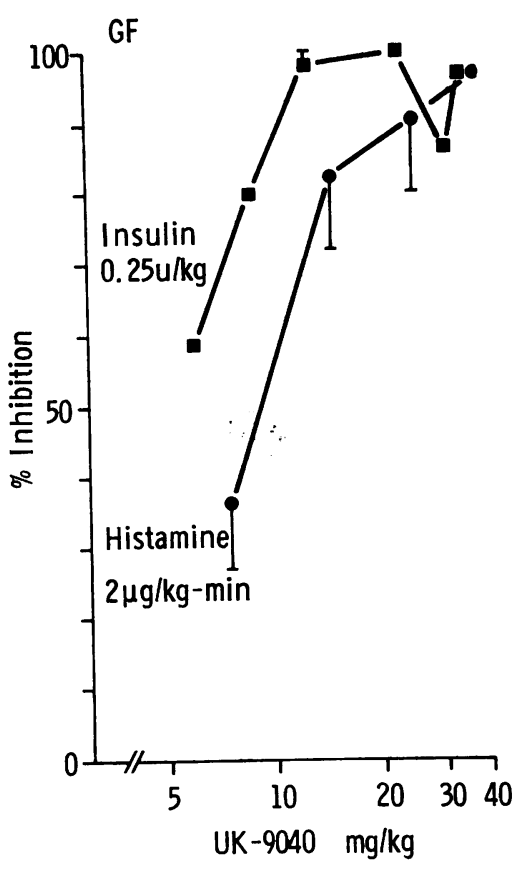

Fig. 3 Inhibition of acid secretion stimulated by histamine $2 \mu \mathrm{g} / \mathrm{kg}$-min and insulin $0.25 \mathrm{u} / \mathrm{kg}$ in dogs with gastric fistula: dose response.

\section{$N$-methyl histamine}

In the control studies it was found that $\mathrm{N}$-methyl histamine in a dosage of $1 \mu \mathrm{g} / \mathrm{kg}$-min produced acid outputs comparable with those after histamine in a dosage of $2 \mu \mathrm{g} / \mathrm{kg}$-min. Complete inhibition of gastric acid secretion from the innervated stomach and $97 \%$ inhibition of gastric acid secretion from the Heidenhain pouch were observed.

\section{Pentagastrin}

The denervated pouch was again more sensitive than the innervated stomach to inhibition by UK-9040 of pentagastrin stimulated gastric acid secretion (Figs. 4 and 5). The dose response curve to pentagastrin may have been shifted to the right in the presence of UK-9040 (Fig. 6).

\section{Duration of inhibition}

Significant inhibition of histamine stimulated acid secretion from the gastric fistula was observed within one hour of oral administration of UK-9040 (Fig. 7). Maximal inhibition was observed between four and six hours (Fig. 8). Inhibition of approximately $\mathbf{5 0 \%}$ was still present when UK-9040 was administered 24 hours before the histamine infusion, but after 48 hours the drug was no longer effective (Fig. 8). 

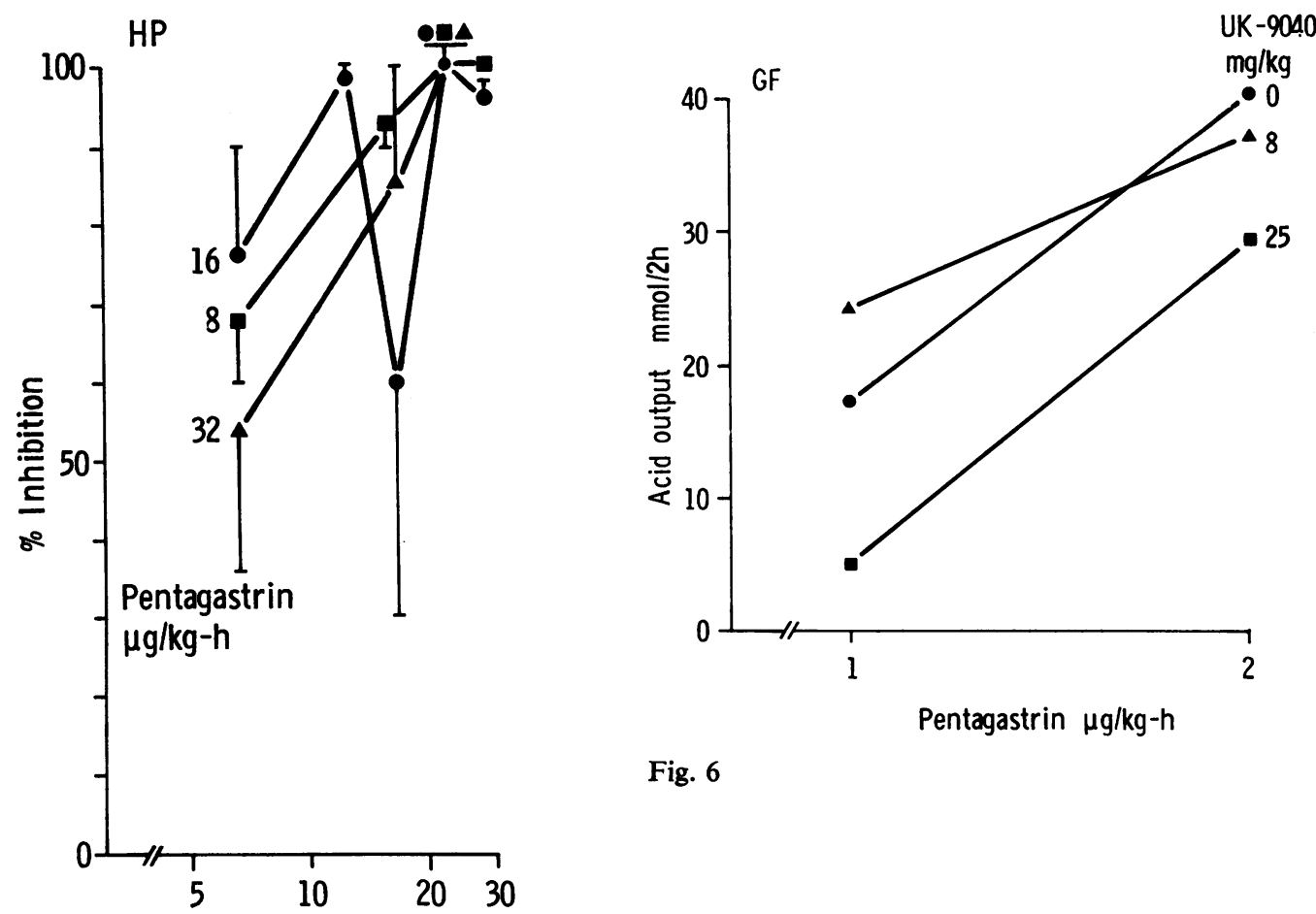

Fig. 6

Fig. 4

$$
\text { UK-9040 mg/kg }
$$

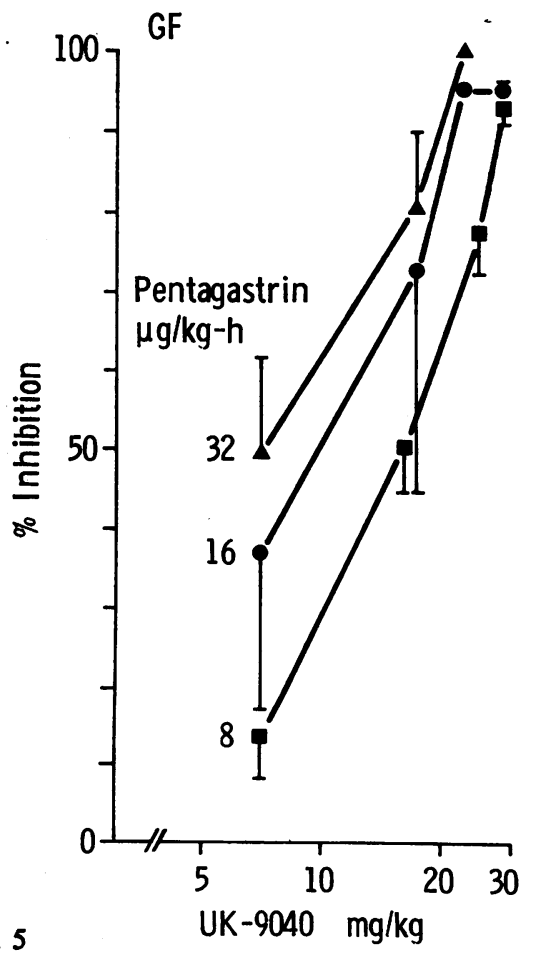

Fig. 4 Inhibition of acid secretion stimulated by pentagastrin 8-32 $\mu \mathrm{g} / \mathrm{kg}-\mathrm{h}$ in the denervated preparation: dose response.

Fig. 5 Inhibition of acid secretion stimulated by pentagastrin 8-32 $\mu \mathrm{g} / \mathrm{kg}-\mathrm{h}$ in the gastric fistula: dose response.

Fig. 6 Mean acid output in response to pentagastrin 1 and $2 \mu \mathrm{g} / \mathrm{kg}-\mathrm{h}$ in control studies and after UK-9040, 8 and $25 \mathrm{mg} / \mathrm{kg}$.

Fig. 5 


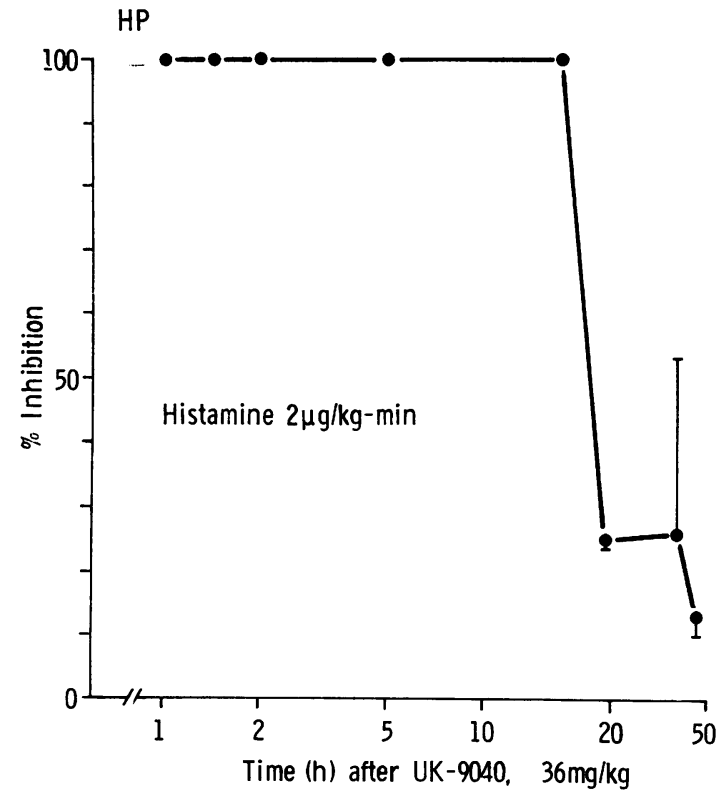

Fig. 7 Inhibition of acid secretion stimulated by histamine $2 \mu \mathrm{g} / \mathrm{kg}$-min in the denervated preparation. Duration of inhibition after UK-9040, $36 \mathrm{mg} / \mathrm{kg}$.

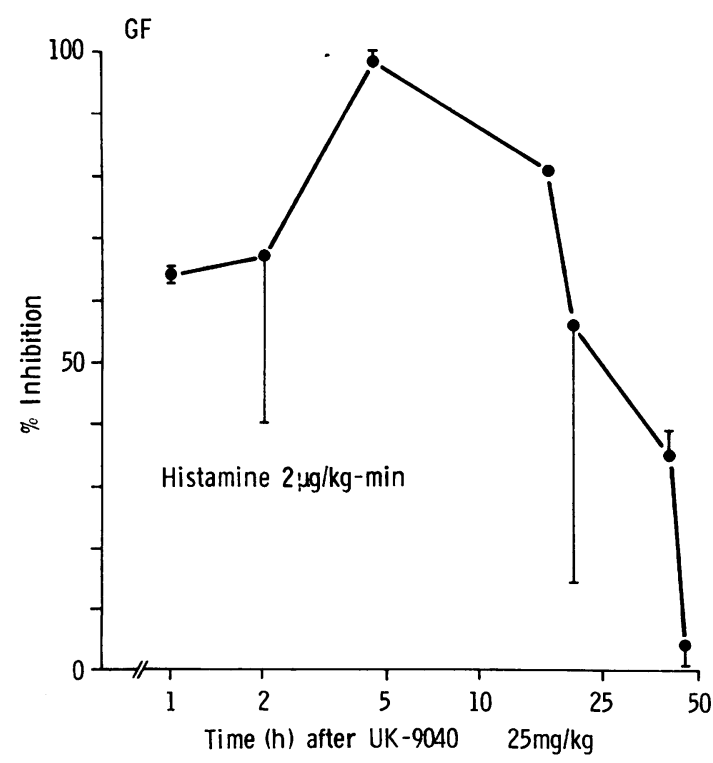

Fig. 8 Inhibition of acid secretion stimulated by histamine $2 \mu \mathrm{g} / \mathrm{kg}$-min in the gastric fistula. Duration of inhibition after UK-9040, $36 \mathrm{mg} / \mathrm{kg}$.
Inhibition of acid output from the denervated pouch was more marked and more sustained (Fig. 7).

\section{Tolerance}

The dog treated with UK-9040 daily for three months did not show any evidence of tolerance to the inhibitory effects of UK-9040 on gastric acid secretion, nor was there evidence of a cumulative effect. Gastric acid secretion reverted rapidly to normal after withdrawal of UK-9040.

GASTRIC SECRETION STUDIES-VOLUME AND PEPSIN OUTPUT

Similar dose-response relationships to those for acid secretion were observed.

MORPHOLOGICAL STUDIES

No abnormality was noted in the light microscopy appearances of 46 biopsies taken from a range of control and inhibitory experiments. Ten pairs of biopsies which showed good preservation of morphological detail and at least six parietal cells in each biopsy, were selected for electron microscopy. Each pair consisted of a biopsy taken before and during stimulation. There were four pairs of control biopsies and six pairs from dogs receiving UK-9040. In the control series at least $75 \%$ of the parietal cells in each biopsy examined before stimulation showed an abundance of smooth surfaced tubulovesicles and small numbers of intracellular canaliculi lined by microvilli (Fig. 9). After gastric secretory stimulation there was a decrease, or a disappearance, of tubulovesicles and an increase in the size of the intracellular canaliculi and the number of microvilli (Fig. 10). These changes were independent of the stimulant used.

In contrast, in the dogs which had received UK-9040 before stimulation of gastric secretion, $70 \%$ of the parietal cells in every biopsy studied failed to show the changes associated with stimulation. Their intracellular structure remained in the resting stage (Fig. 11). This phenomenon was also independent of the method of stimulation. The morphology of the parietal cells of a dog on longterm UK-9040 was identical with that seen in the acute experiments.

CARDIOVASCULAR STUDIES

Blood pressure and pulse rate were neither affected by bolus injection of insulin, nor intravenous infusion of pentagastrin, histamine, or $\mathrm{N}$-methyl histamine. Administration of UK-9040 before the secretagogues was not associated with a change in pulse rate or blood pressure. 


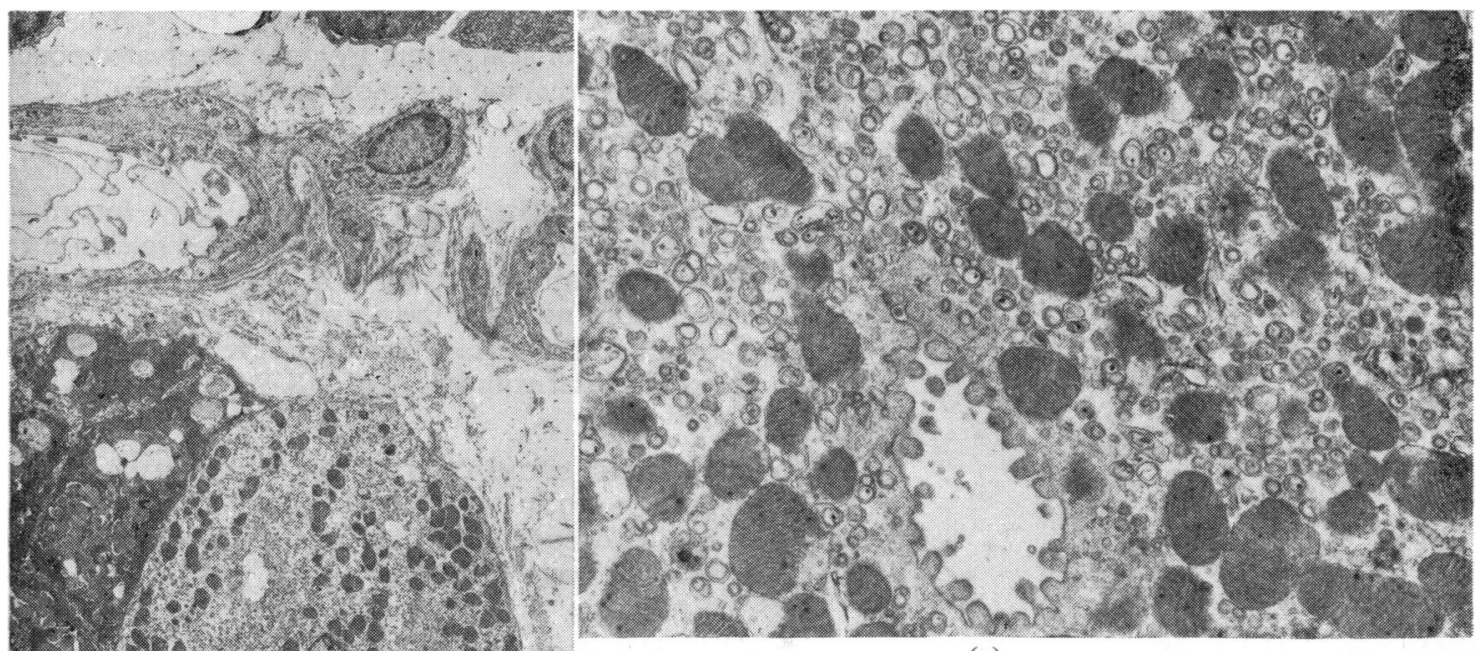

(a)

Fig. 9 A normal resting parietal cell (Electron microscopy (a) $\times 2000$, (b) $\times 10000$ ). There are abundant tubulovesicles and the intracellular canaliculi contain only few microvilli. (b)

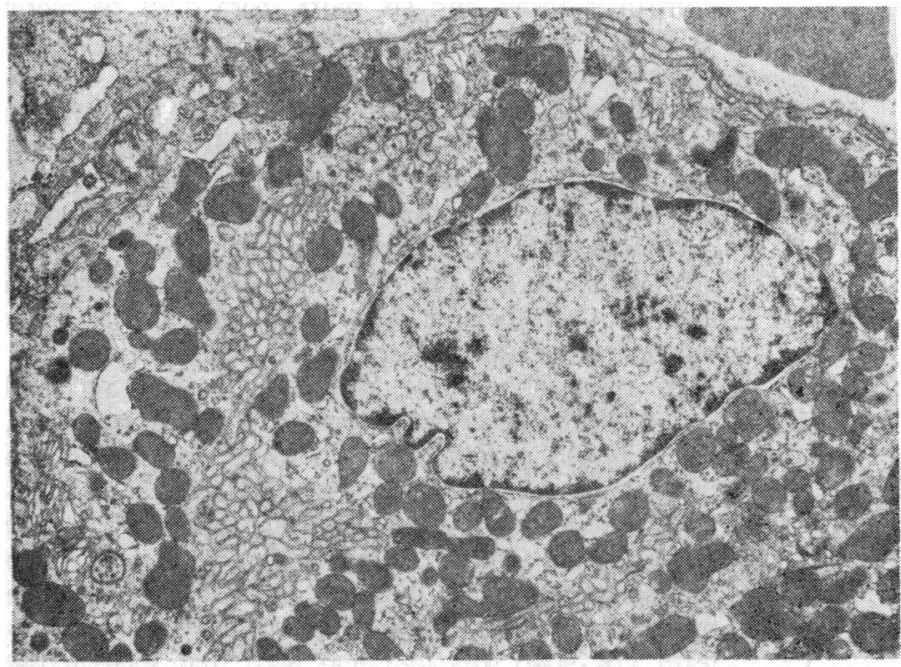

(a)

Fig. 10 A stimulated parietal cell (after pentagastrin $4 \mu \mathrm{g} / \mathrm{kg}$-min). (Electron microscopy (a) $\times 5000$, (b) $\times 20$ 000.) The intracellular canaliculi are convoluted with many microvilli and the tubulovesicles are greatly reduced.

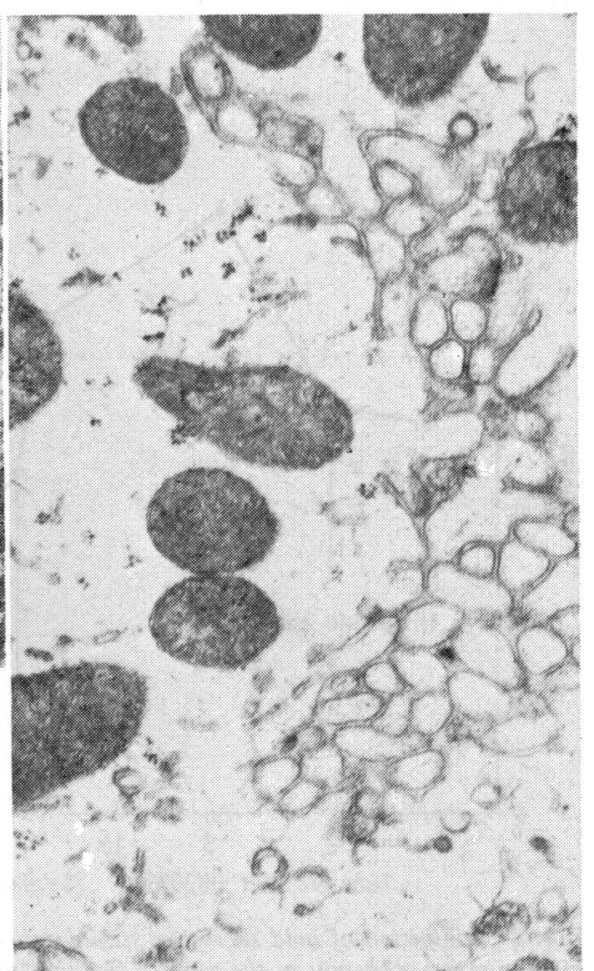

(b) 


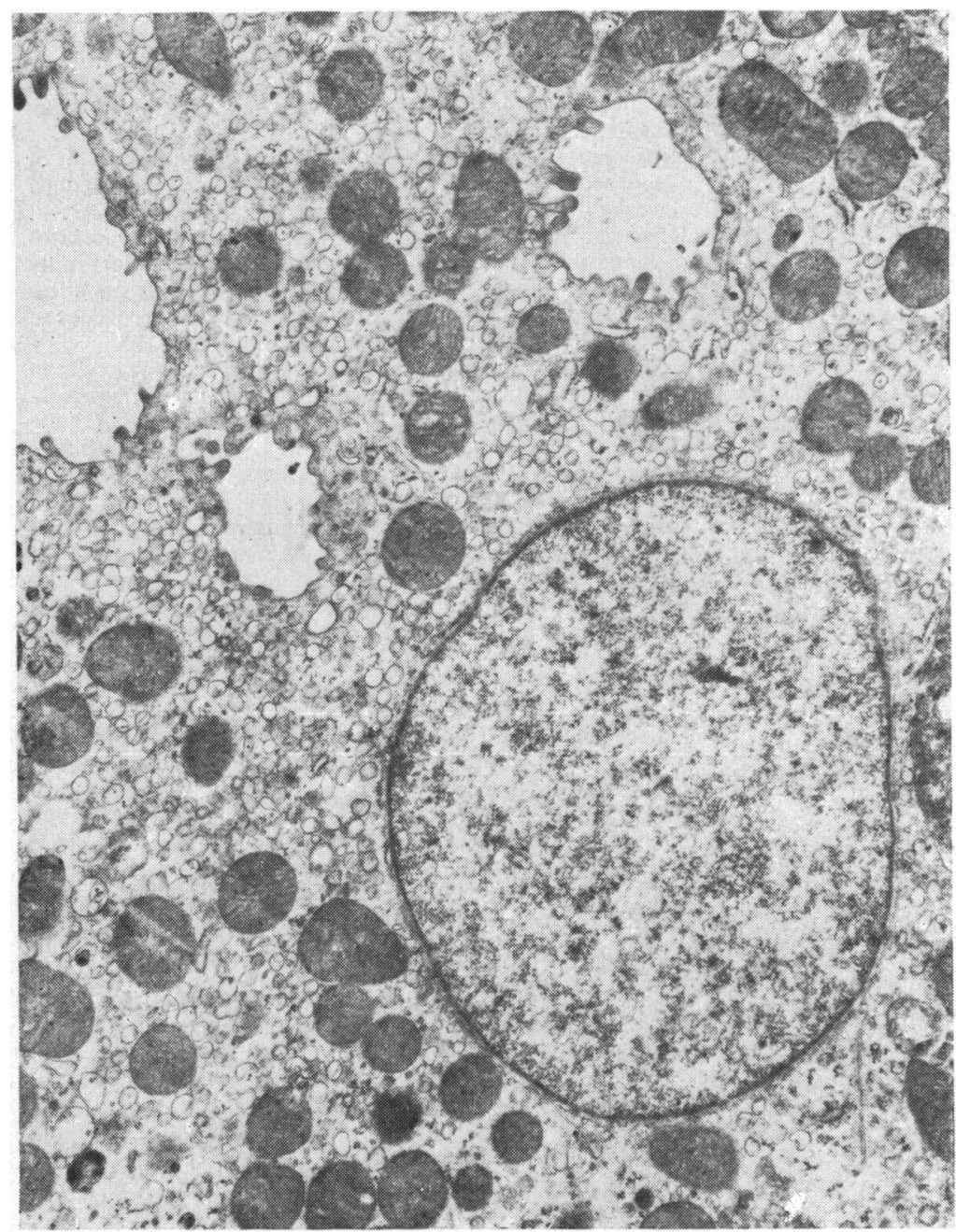

Fig. 11 Gastric parietal cell stimulated by histamine 2 $\mu g / k g$-min $6 \frac{1}{2}$ hours after UK-9040 $30 \mathrm{mg} / \mathrm{kg}$. The cell structure is similar to the resting parietal cell. Electron microscopy. $\times 5000$.

\section{Discussion}

An ideal gastric secretory inhibitor should inhibit both acid secretion and volume as well as decreasing pepsin activity. The minimum requirements stipulated by McKenna et al. (1964) for such an agent were that there should be $50 \%$ inhibition for at least 30 minutes. UK-9040 easily satisfies these criteria when given orally to dogs; it is a powerful and sustained inhibitor of gastric secretion stimulated by histamine, food, pentagastrin, $\mathrm{N}$-methyl histamine, and insulin. This inhibition is not mediated via a hypotensive action, unlike that of hexamethonium bromide (Caridis and Smith, 1968). The morphological changes that occurred in the present study after stimulation of the parietal cells are similar to those previously reported (Helander, 1962; Ito and Winchester, 1963; Rosa, 1963; Sedar, 1965; Adkins et al., 1966, 1967; Helander and Hirschowitz, 1972). There was a decrease in the number of tubulovesicles and an increase in the size of the intracellular canaliculi and the number of microvilli (Sedar and Friedman, 1961; Helander, 1964). Like other authors (Ito, 1961), we considered the variable appearance of dilated or collapsed canaliculi and circular or tubular vesicles to be a fixation artefact.

UK-9040 prevented the characteristic morphological response to gastric stimulation in $70 \%$ of the parietal cells studied. The precise mechanisms of acid secretion are unknown, but one step is the incorporation of the tubulovesicular membrane into the intracellular canaliculi (Leeson, 1973). This in- 
corporation gives a greatly increased surface area for ionic exchange in the cell and is a feature of the secretory cells of many animal species (Philpott and Copeland, 1963; Sedar, 1969).

The effect of UK-9040 at an ultrastructural level is similar to that of other antisecretory agents. For example, the formation of microvilli and subsequent increase in surface area of the canaliculi was similarly inhibited after the administration of 2:4 dinitrophenol, an oxidative uncoupling agent (Vial and Orrego, 1963), acetazolamide, an inhibitor of carbonic anhydrase (Sedar, 1962), and glycopyrrolate, an anticholinergic (Posey et al., 1968). It is not clear what these different types of inhibitory substances have in common, but we postulate that the incorporation of the tubulovesicular membranes into the canaliculi is likely to be one of the final events in secretion of acid, as four unrelated compounds, presumably active at different sites, produce the same ultrastructural effects. The mode of action of UK-9040 remains uncertain and the studies do not resolve the problem of whether acid secretion is mediated solely through histamine (MacIntosh, 1938) or through the interaction of more than one receptor (Grossman and Konturek, 1973).

These studies have shown that this new compound, UK-9040, is a powerful sustained inhibitor of acid secretion both pharmacologically and morphologically. No cellular damage was seen after chronic administration and the normal morphological appearances quickly reappeared when the drug was withdrawn. UK-9040 has not been developed for use in man because of cardiotoxicity, but it is hoped that further inhibitory drugs of this series might provide the basis for an entirely new and effective approach to the hypersecretory diatheses.

We wish to thank Pfizer Central Research, Sandwich, England, for their support, and Eli Lilly for the $\mathrm{N}$-methyl histamine.

\section{References}

Adkins, R. B., Ende, N., and Gobbel, W. G. (1966). Ultrastructural alterations of the gastric mucosa following gastrin administration. Surgical Forum, 17, 297-299.

Adkins, R. B., Ende, N., and Gobbel, W. G. (1967). A correlation of parietal cell activity with ultrastructural alterations. Surgery, 62, 1059-1069.

Black, J. W., Duncan, A. M., Durant, C. J., Ganellin, C. R., and Parsons, E. M. (1972). Definition and antagonism of histamine $\mathrm{H}_{2}$-receptors. Nature, 236, 385-390.

Caridis, D. T., and Smith, G. (1968). Gastric secretion and anticholinergic drugs. British Journal of Surgery, 55, 185-189.

Grossman, M. I., and Konturek, S. J. (1974). Inhibition of acid secretion in dog by metiamide, a histamine antagonist acting on $\mathrm{H}_{2}$ receptors. Gastroenterology, 66, 517-521.

Helander, H. F. (1962). Ultrastructure of fundus glands of the mouse gastric mucosa. An electron microscopical study in fasted and re-fed animals with observations on ultrastructure after different fixation and embedding procedures. Journal of Ultrastructure Research, suppl. 4, 1-123.

Helander, H. F. (1964). Ultrastructure of secretory cells in the pyloric gland area of the mouse gastric mucosa. Journal of Ultrastructure Research, 10, 145-159.

Helander, H. F., and Hirschowitz, B. I. (1972). Quantitative ultrastructural studies on the gastric parietal cells. Gastroenterology, 63, 951-961.

Ito, S. (1961). The endoplasmic reticulum of gastric parietal cells. Journal of Biophysical and Biochemical Cytology, 11, 333-347.

Ito, S., and Winchester, R. J. (1963). The fine structure of the gastric mucosa in the bat. Journal of Cell Biology, 16, 541-577.

Leeson, T. S. (1973). Canaliculi and tubulovesicles of rat parietal cells. American Journal of Anatomy, 136, 541-547.

Macintosh, F. C. (1938). Histamine as a normal stimulant of gastric secretion. Quarterly Journal of Experimental Physiology, 28, 87-98.

McKenna, R. D., Smith, S. A., and Wyse, D. M. (1954). The effects of newer antisecretory compounds on gastric secretion and motility in man and dogs. Gastroenterology, 26, 476-489.

Philpott, C. W., and Copeland, D. E. (1963). Fine structure of chloride cells from three species of fundulus. Journal of Cell Biology, 18, 389-404.

Posey, E. L., Elliott, R., Shewmake, B., and Posey, L. (1968). Comparative effect of long term anticholinergic administration with glycopyrrolate and of vagotomy on parietal cell function, ultrastructure and population. American Journal of Digestive Diseases, 13, 515-526.

Rosa, F. (1963). Ultrastructure of the parietal cell of the human gastric mucosa in the resting state and after stimulation with histalog. Gastroenterology, 45, 354-363.

Sedar, A. W. (1962). The fine structure of the oxyntic cells in relation to functional activity of the stomach. Annals of the New York Academy of Sciences, 99, 9-29.

Sedar, A. W. (1965). Fine structure of the stimulated oxyntic cell. Federation Proceedings, 24, 1360-1367.

Sedar, A. W. (1969). Electron microscopic demonstration of polysaccharides associated with acid secreting cells of the stomach after 'inert' dehydration. Journal of Ultrastructure Research, 28, 112-124.

Sedar, A. W., and Friedman, M. H. (1961). Correlation of the fine structure of the gastric parietal cell (dog) with functional activity of the stomach. Journal of Biophysical and Biochemical Cytology, 11, 349-363.

Vial, J. D., and Orrego, H. (1963). Action of 2,4-Dinitrophenol and iodoacetate on the ultrastructure of the oxyntic cells. Experimental Cell Research, 30, 232-235. 